\title{
Exchange Rate Pass-Through in Ghana
}

\author{
Siaw Frimpong \\ School of Business, University of Cape Coast, Cape Coast, Ghana \\ E-mail: frisiman@yahoo.com \\ Anokye M. Adam \\ School of Business, University of Cape Coast, Cape Coast, Ghana \\ E-mail: ano77chie@yahoo.co.uk
}

\begin{abstract}
The paper examines the effect of exchange rate changes on consumer prices in Ghana using vector autoregression (VAR) models. Using a data set covering the period 1990M01-2009M02, we find that the exchange rate pass-through to inflation is 'incomplete' and decreasing in Ghana. Our empirical results indicate a low but significant pass-through in the short run. We argue that the findings reflect the impact of increased openness and tighter monetary policy pursue by the central bank over the period.
\end{abstract}

Keywords: Pass-through, Exchange rate, Inflation, Impulse response

JEL Classification Numbers: C32, E31, E 41, O55

\section{Introduction}

One of the most challenging problems in developing countries such as small open economy of Ghana is exchange rate pass-through (ERPT).The expression 'exchange rate pass-through' is generally used to refer to the effect of exchange rate changes on one of the following: (1) import and export prices, (2) consumer prices, (3) investments and (4) trade volumes. Due to its importance in international finance and monetary policy, it has become focus of interest for policymakers and academics alike. The later is primary interested in the role of ERPT in understanding the mechanisms of international price adjustment, e.g. in reconciling the observation that the relative stability of import prices does not reflect the high volatility of nominal exchange rates with economic theory. Along with policymakers, they are primarily interested in the extent and timing of ERPT as a key ingredient of monetary policy and forecasting models of prices. For example in the conduct of monetary policy, the ability of a central bank to respond adequately to different shocks requires an understanding of the transmission mechanism of monetary policy. In a small open economy such as Ghana, the exchange rate provides an important transmission channel for monetary policy, in addition to the standard aggregate demand channel Evidence of 'disconnect' between exchange rates and prices would also imply a greater degree of insulation and thus greater effectiveness of monetary policy.

According to Goldberg and Knetter (1997) exchange rate pass-through is defined as "the percentage change in local currency import prices resulting from a one percent change in the exchange rate between the exporting and importing countries." Extensive empirical researches exist on the theme across the globe with most of them being the developed or emerging economies (Note 1). The most important to policy makers is whether pass-through is complete; defined as one-to-one response of domestic prices to exchange rate changes.

Abundant empirical evidence has indicated that the exchange rate pass-through to either the import price or the consumer price index (CPI) is incomplete, see for example Engel and Rogers (1996), and Parsley and Wei(2001)

In Africa Choudhri and Hakura (2001) find that the level of inflation dominates the volatility of inflation and the exchange rate as an explanation of cross-country differences in the pass-through. They find zero pass-through to inflation in Ethiopia and incomplete passthrough in other African countries during the period 1997-2000. Canetti and Greene (1992) find that exchange rate movements and monetary expansion affect consumer price inflation in sub-Saharan Africa (SSA). In particular, they find that exchange rates have a significant "Granger causal" impact on prices in Tanzania, Sierra Leone, and Democratic Republic of Congo. This is linked to the high inflation episodes in these economies. They find that monetary expansion "Granger causes" inflation in the Gambia and Uganda. Kiptui, Ndolo, and Kaminchia (2005) find that pass-through in Kenya during the period 1972-2002 is incomplete. An exchange rate shock leads to a sharp increase in CPI inflation; however, this dies out after four years. Exchange rate shocks account for 46 percent of the variation in inflation in the first year, peaking at 57 percent in the third year. 
In import dominated economy such as Ghana, the level of the exchange rate pass-through could be different. In the second quarter of 2009, fuel prices were adjusted upward to compensate for the depreciation of cedi against the dollar in Ghana. This gives a reason to suspect the severity of exchange rate pass-through in Ghana.

In this context, this paper utilizes vector error correction (VEC) models and Granger causality tests to examine the level of exchange rate pass-through to domestic prices in Ghana which is missing in the literature. The result of our study have serious policy implication in that a low exchange rate pass-through is thought to provide greater freedom for pursuing an independent monetary policy and facilitates inflation targeting

The empirical findings indicate an incomplete exchange rate pass-through to inflation in Ghana during the period 1990:1-2009:2. A one percent depreciation is associated with a 0.025 percent increase in inflation after a quarter after initial impact. The effect of the pass-through increases to 0.09 percent after eight quarters. The effect decreases sluggishly and stayed around 0.07 per cent after twelve quarters of its initial impact. The pass-through to inflation during this period is persistent, implying that exchange rate movements have a small but prolonged impact on inflation

The remainder of the paper is organized as follows. Section 2 gives the model, empirical methodology and data. The results are discussed in Section 3; concluded and summarised in section 4.

\section{Model}

We begin our analysis by considering PPP relation in logs i.e.

$$
P^{d}=\varphi e_{t}+\lambda p^{f}
$$

where $e_{t}$ is the nominal (dollar) exchange rate expressed in domestic currency, $p^{d}$ and $p^{f}$ are the domestic and foreign price levels respectively, and all variables are expressed in logarithms.

The "law of one price" implies that $\varphi=\lambda=1$ in which case changes in the exchange rate completely pass through to the domestic price of the traded good. This simple expression forms the basis of analyzing the long run pattern of exchange rate pass-through.

We follow McFarlane (2002), and Parsely and Popper (1998) with little deviation, the paper extends this expression to take account of the Central Bank's behaviour, unlike the formers we include interest rates. This is in-support of Bernanke and Mihov (1997) that most central banks in the world by now target short-term interest rates.

$$
P^{d}=\varphi e_{t}+\lambda p^{f}+i^{d}
$$

Central banks that target consumer price inflation will try to insulate prices from exchange rate movements. Neglecting the behaviour of policy variables may distort the true consequences of exchange rate variations on consumer prices. By including policy variables, the observed relationship between prices and exchange rates would take into account the central bank's behaviour rather than the direct influence of exchange rates on prices.

A cointegrated time series system has an equivalent vector error correction (VEC) representation according to Engle and Granger (1987). The relation (2) is estimated in the vector error correction form

$$
\Delta Y_{t}=\mu+\Pi Y_{t-1}+\Gamma_{1} \Delta Y_{t-1}+\ldots+\Gamma_{k-1} \Delta Y_{t-k+1}+\lambda \Delta p^{f}+u_{t}
$$

Where $Y_{t}=\left[e_{t}, p_{t}, i\right], \Delta=1-L, \Pi$ can be written as $\Pi=\alpha \beta^{\prime}, u_{t}$ is a white noise innovations with $E\left(u_{t} u_{t}\right)^{\prime}=\Omega$ and $p^{f}$ enters exogenously since the domestic economy is a price taker. Our VEC model specifically takes the form

$$
\Delta p_{t}^{d}=\mu+\alpha z_{t-1}+\sum_{i=1}^{k} \varphi_{i} \Delta e_{t-i}+\sum_{q=0}^{k} \gamma_{q} \Delta i_{t-q}+\lambda \Delta p^{f}+u_{t}
$$

where $Z_{t-1}$ represents the error correction term with coefficients, $1>\alpha_{1}>0$ and $1>\alpha_{2}>0$.

The time series properties of the data are analyzed using the (DF-GLS and ADF) and one stationarity test (KPSS). Elliot et al (1996) devised the DF-GLS test which is more efficient than the usual ADF. The KPSS tests the null of stationarity, whereas ADF and DF-GLS tests the null of a unit root. If the KPSS test rejects the null but ADF and DF-GLS test does not, we can say that all the three tests support the same conclusion; that is, the series in question is an I (1) process. The Johansen (1991) full information maximum likelihood procedure is used to estimate the VECM and to test cointegrating rank of $\mathrm{P}$. 
Impulse response functions and variance decompositions are utilized to assess the pass-through from exchange rate fluctuations to domestic inflation. Impulse response functions trace the effects of a shock emanating from an endogenous variable to other variables through the dynamic structure of the VECM. Variance decompositions measure the percentage of the forecast variance in inflation that can be attributed to various shocks.

Following Pesaran and Shin (1996), the impulse response function of $p_{t}^{d}$ (denoted by $\psi_{p^{d} c}$ ) with respect to a unit composite innovation $\beta^{\prime} u_{t}$ can be obtained from the VEC model as follows:

$$
\psi_{p^{d}} c(t)=\left\{\left(\beta^{\prime} C_{t} \Omega C_{t}^{\prime} \beta\right)\left(\beta^{\prime} \Omega \beta\right)^{-1}\right\}^{1 / 2}
$$

where $C_{t}$ is defined by the recursive equation

$$
C_{t}=A_{1} C_{t-1}+A_{2} C_{t-2}+\ldots+A_{k} C_{t-k} t=1,2, \ldots
$$

with $C_{0}=1$ and $C_{t}=0$ for $t<0$

$\left\{C_{t}, t=1,2, \ldots\right\}$ constitutes the coefficient matrices of the moving-average representation of $Y_{t}$. Based on $\psi_{p^{d}{ }_{c}}$ we compute the first 24 impulse responses, which correspond to a time span of 6 years for quarterly data..

The generalized impulse response approach recommended by Pesaran and Shin (1998) is applied. Unlike traditional impulse response analysis (e.g. Lutkepohl and Reimers, 1992), which considers orthogonalised shocks based on the Cholesky decomposition, the new approach desirably yields unique impulse response functions (IRFs) that are invariant to the ordering of variables. The generalized IRF for $Y_{t}=\left[p_{t}^{d}, e_{t}, i_{t}\right]$ with respect to a unit innovation to the $j t h$ variable $(j=1$ for a nominal exchange rate innovation and 2 for a price innovation) is given by

$$
\psi_{Y j}(t)=C_{t} \Omega_{\gamma j} / \sigma_{j j} \quad t=0,1,2, \ldots
$$

where $C_{t}$ is computed from (6) recursively, $\gamma j$ is a selection vector with unity as the $j$ th element and zeros elsewhere and $\sigma_{j j}$ is the $j t h$ diagonal element of $\Omega \cdot \psi_{Y j}(t)$ which gives the separate IRFs for nominal exchange rate and price adjustments. The generalized IRF for real exchange rate adjustment in response to a unit innovation to the $j$ th variable is given by

$\psi_{p^{d} j}(t)=\beta^{\prime} C_{t} \Omega_{j j} / \sigma_{j j}, t=0,1,2, \ldots$

An increase in $p_{t}^{d}$, for example, can be induced by either a negative innovation to $i_{t}$ or a positive innovation to $e_{t}$ In fact, the IRFs of $P_{t}^{d}, e_{t}$, and $i_{t}$ are linked to one another as follows:

$\psi_{p^{d} j}(t)=\psi_{e j}(t)-\psi_{i j}(t), t=0,1,2, \ldots$

The Variance decomposition which measures the percentage of the forecast variance in inflation that can be attributed to various shocks is achieved by the Cholesky decomposition, which imposes restrictions on the residual variance covariance matrix and assumes that the errors are orthogonal.

\section{Data}

The empirical analysis is conducted using quarterly data, which provides a reasonable sample size to study the exchange rate/inflation dynamics in the post 1990 period. The time span covered is first quarter of 1990 to second quarter of 2009. Inflation is measured by the log of the consumer price index $\left(p^{d}\right)$ ), Exchange rate data are weighted average nominal exchange rates $\left(e_{t}\right)$ of the Ghana Cedi per U.S. dollar. The U.S. dollar was used since it is the currency of Ghana's major trading partner. The Treasury bill rates (average discount rates on 3-month instruments) $(i)$ is used to reflect changes in the Central Bank's behaviour. The U.S. consumer price index $\left(p^{f}\right)$ is used as levels of foreign prices. All the data used are quarterly data obtained from the International Financial Statistics of the IMF (IFS, October, 2009 online edition). A plot of the logarithms of all the series is shown in Figure 1. The evidence from Figure 1 indicates varied behaviour of all the variables within. The cedi/dollar exchange rate has shown has shown a general upward trend. Domestic prices were volatile between 1990 and 2009. 


\section{Empirical Results}

Table 1 gives the complete test statistics for the unit root tests. As indicated by the ADF and DF-GLS, the null of unit root in all the variables cannot be rejected at the $1 \%$ level.

The KPSS test for all the variables under consideration in indicate that the null of stationary under KPSS is soundly rejected at the $1 \%$ level. These results are robust to alternative specifications such as including a time trend in the regression equations, and correction for residual correlation.

\section{Estimates from VEC approach}

Using the VEC approach, the long-run pass-through effect from

Exchange rate to domestic prices is estimated. The lag length of two was selected using the Schwarz information criterion. Additionally, the AR root lag structure indicates that no root lies outside the unit circle; hence the VAR satisfies the stability condition.

Table 2 and Table 3 report the results of the Johansen tests and the normalized values of the long run matrix, $\beta$, respectively. All coefficients have their anticipated (or at least plausible) signs. The coefficient of the exchange rate which could be interpreted as the long-run pass-through coefficient is not significant, indicating low/absence of exchange rate pass-through in the long run.

The decrease in inflation reflects the change in policy stance, in particular, tightening of fiscal and monetary policy. It is evident that interest has a stronger impact on prices than the exchange rate.

The short-run dynamics (see Table 4) suggest that the speed of adjustment of inflation to its long-run equilibrium has a half life of about 3.5 quarters. The coefficient on the lagged error correction term for inflation is -0.1403 . This means that if inflation exceeds its long run equilibrium by 1 percentage point, for example because of a temporary exchange rate shock, 14.03 percent of this deviation is adjusted for every quarter, so it takes about 7 quarters for inflation to adjust to its long-run equilibrium. Another interesting finding is the significant impact of foreign prices on domestic prices. One percent increase in foreign prices decrease domestic prices by 0.07 percent.

\section{Impulse Response and Variance Decomposition}

The impulse response functions indicate a low degree of exchange rate pass-through effect to inflation that levels around $7 \%$ to $100 \%$ shock in exchange rate after a long period (Table 5, Figure 2). An exchange rate depreciation, a positive exchange rate shock, results in a increase in inflation after a four-quarter lag and peak after eight-quarter. However, the pass-through though significant is low, with a 10 percent exchange rate appreciation resulting in a 0.9 percent decrease in inflation, at eight-quarter (Table 5, Figures 2 ). This is consistent with the variance decomposition (see Table 6), indicating the increase in domestic prices are mainly attributing to its own variations and interest rate in the long run, suggesting that the inflation process in Ghana has significant inertia.

\section{Conclusion}

The purpose of this paper is to investigate the level of exchange rate pass-through in Ghana using time series data from 1990:Q1 to 2009:Q2

First, the Johansen cointegration approach was employed to determine the long run relationship of domestic prices, interest rate, and Cedi/dollar exchange. The results indicate that the null of no cointegration cannot be accepted when domestic prices is the dependent variable. We find long run positive and insignificant relationship between domestic prices and exchange rate; indicating that the long-run exchange rate pass-through in Ghana is zero.

The paper also finds an incomplete and decreasing exchange rate pass-through to inflation in Ghana, consistent with findings on other African countries. Our empirical results indicate a low but significant pass-through in the short-run.

We argue that the findings reflect the impact of increased openness and tighter monetary policy pursue by the central bank over the period. The findings imply that the authorities should remain vigilant in assessing the potential impact of Central Bank policy on the dynamics of inflation in Ghana. In this regard, the authorities should seek to maintain low and stable Interest rate and continue the ongoing tighter monetary policy designed to curb interest rate volatility.

It should be noted however, that in spite of the low level of the pass through, the results suggest that the influence of exchange rate movements is still significant for domestic prices. While the lower degree of 
pass-through allows for some flexibility in policy, continued emphasis has to be placed on reducing volatility and moderating the speed of adjustments.

\section{References}

Bernanke, B.S. and I. Mihov. (1997). What does the Bundesbank target? European Economic Review 41, 1025-1053.

Canetti, E. and J. Greene. (1992). "Monetary Growth and Exchange Rate Depreciation as Causes of Inflation in African Countries: An Empirical Analysis," Journal of African Finance and Economic Development, Vol. 1, pp. $37-62$.

Choudhri, E. and D. Hakura. (2001). "Exchange Rate Pass-through to Domestic Prices: Does the Inflationary Environment Matter?” IMF Working Paper No. 01/194 (Washington: International Monetary Fund).

Engel, C. (2001). The Responsiveness of Consumer Prices to Exchange Rates and the Implication for Exchange Rate Policy: A Survey of a Few New Open-Economy Macro Models, University of Wisconsin and NBER.

Engle, R.F. and C.W.J. Granger. (1987). Cointegration and Error Correction: Representation, Estimation and Testing, Econometrica, 49: 1057-1072.

Goldberg, P. and M. Knetter. (1997). "Goods Prices and Exchange Rates: What Have We Learned?" Journal of Economic Literature, Vol. 35, No. 3, pp. 1243-72.

Granger, C.W.J. (1969). "Investigating Causal Relations by Econometric Models and Cross Spectral Methods," Econometrica, Vol. 37, pp. 428-38.- 33.

International Monetary Fund. (2008). International Financial Statistics. Washington, D.C.: International Monetary Fund.

Johansen, S. (1988). "Statistical Analysis of Cointegrated Vectors," Journal of Economic Dynamics and Control, Vol. 12, pp. 231-54.

Johansen S. (1991). Estimation and Hypothesis Testing of Cointegration Vectors in Gaussian Vector Autoregressive Models, Econometrica, 59.

Kiptui, M., D. Ndolo, and S. Kaminchia. (2005). "Exchange Rate Pass-Through: To What Extent Do Exchange Rate Fluctuations Affect Import Prices And Inflation In Kenya?" Policy Discussion Paper No. 1 (Nairobi: Central Bank of Kenya).

Kwiatkowski, D., P.C.B. Phillips, P. Schmidt and Y. Shin. (1992). Testing the null hypothesis of stationarity against the alternative of a unit-root: How sure are we that economic series have a unit root? Journal of Econometrics 54, 159-178.

Lavern McFarlane. (2002). "Consumer Price inflation and Exchange rate Pass-through in Ghana" Research Services Department, Bank of Jamaica.

Lutkepohl, H. and Reimers, H.E. (1992). "Impulse Response Analysis of Cointegrated Systems," Journal of Economic and Dynamic Controls, 16, 53-78.

Nkunde Mwase. (2006). "An Empirical Investigation of the Exchange Rate Pass-Through to Inflation in Tanzania” IMF Working Paper WP/05 /150 (Washington: International Monetary Fund).

Osler, C. (1998). Short-term speculators and the puzzling behavior of exchange rates, Journal of International Economics, 43: 37-57.

Parsley, D.C. and H.A. Popper. (1998). Exchange rates, domestic prices, and central bank actions: recent U.S. experience, Southern Economic Journal, 64 (4). 957-972.

Takhtamanova ,Y. (2008). Understanding Changes in Exchange Rate Pass-Through Federal Reserve Bank of San Francisco Working Paper 2008-13 Federal Reserve Bank of San Francisco, San Francisco.

Taylor, J. (2000). "Low Inflation, Pass-Through, and the Pricing Power of Firms," European Economic Review, Vol. 44, No. 7, pp. 1389-1408. Framework Concept Paper” (Washington: International Monetary Fund).

\section{Notes}

Note 1. See Mwase (2006), McFarlane (2002), Osler (1998), Kiptui, Ndolo, and Kaminchia (2005); Choudhri and Hakura (2001), Takhtamanova (2008) for detailed literature on ERPT 
Table 1. Univariate Unit root test on natural logarithms of the variables

\begin{tabular}{|c|c|c|c|c|c|c|c|c|}
\hline & $\begin{array}{l}e_{t} \\
\text { Levels }\end{array}$ & First Diff & $\begin{array}{l}i_{t} \\
\text { Levels }\end{array}$ & First Diff & $\begin{array}{c}p_{t}^{d} \\
\text { Levels }\end{array}$ & First Diff & $\begin{array}{c}p_{t}^{f} \\
\text { Levels }\end{array}$ & First Diff \\
\hline DF_GLS & 0.75 & $-4.08^{* *}$ & -2.32 & $-4.52 * *$ & -1.48 & $-6.32 * *$ & -1.19 & $-2.28^{* *}$ \\
\hline $\mathrm{ADF}$ & -1.70 & $-4.06^{* *}$ & -2.39 & $-5.86^{* *}$ & -2.30 & $-6.43 * *$ & -2.48 & $-6.35^{* *}$ \\
\hline KPSS & $1.17 * *$ & 0.246 & $0.54 *$ & 0.10 & $0.34 * *$ & 0.05 & $0.28 * *$ & 0.05 \\
\hline
\end{tabular}

Note: The null hypothesis for the DF-GLS and ADF test is that the data process under examination contains a unit root. Critical values for the DF-GLS are 2.58 and 1.94 for the $1 \%$ and $5 \%$ levels respectively, given by Elliott et al. (1996). Critical values of ADF 1\% and 5\% are -3.43 and -2.86 respectively (see MacKinnon, 1991). KPSS critical values for $1 \%$ and $5 \%$ are 0.73 and 0.46 respectively, from Kwiatkowski et al (1992). **, * indicates significance at the $1 \%$ and 5\% levels respectively. In Both ADF and DF-GLS, lag length of 4 was appropriate, whereas the Newey-West bandwidth was used in the case of KPSS.

Table 2. Multivariate Johansen cointegration Test

\begin{tabular}{|c|c|c|c|c|}
\hline & Lag & $r=0$ & $\mathrm{r} \leq 1$ & $r \leq 2$ \\
\hline$\lambda_{\text {trace }}$ & 2 & $39.28 * *[35.19]$ & $19.72[20.26]$ & $3.11[9.16]$ \\
\hline$\lambda_{\max }$ & 2 & $23.56^{* *} \quad[22.29]$ & $14.62[15.89]$ & $3.11[9.16]$ \\
\hline
\end{tabular}

Note: The null hypothesis for these two tests here is that the data generating processes under consideration are not cointegrated. Critical values in [ ] for both trace and maximum-eigenvalue statistics at the 5\% level are given by MacKinnon-Haugh-Michelis(1999). $\quad * *$ denotes the rejection of the hypothesis at the $1 \%$ level

Table 3. Normalized cointegrating coefficients (t-statistics in parentheses)

\begin{tabular}{llll}
\hline$p_{t}^{d}$ & $e_{t}$ & $i_{t}$ & $\mathrm{c}$ \\
\hline 1.000000 & -0.011614 & $-0.735952^{* *}$ & -1.169551 \\
& {$[-0.13151]$} & {$[-2.76190]$} & {$[-1.17639]$} \\
\hline
\end{tabular}

** denotes 5\% significance level

Table 4. VECM estimation for $P^{d}$

Independent Variables

\begin{tabular}{cccccc}
$\operatorname{Lag}(\mathrm{n})$ & $P^{d}{ }_{t-n}$ & $e_{t-n}$ & $i_{t-n}$ & $P^{f}{ }_{t+1-n}$ & $E_{t-n}$ \\
\hline \multirow{2}{*}{1} & $0.4452 * *$ & -0.5755 & $0.5759 * *$ & $-0.0741 * *$ & $-0.1403 * *$ \\
& {$[3.6612]$} & {$[-1.1116]$} & {$[2.5610]$} & {$[-2.1249]$} & {$[-2.3566]$} \\
2 & 0.04702 & 0.74469 & -0.3896 & & \\
& {$[0.3634]$} & {$[1.4515]$} & {$[-1.5475]$} & & \\
\hline
\end{tabular}

Table 5. Response of domestic prices to one standard deviation of exchange rate

\begin{tabular}{llllllll}
\hline & 1 & 4 & 8 & 12 & 16 & 20 & 24 \\
\hline$i_{t}$ & 0.064475 & 0.181802 & 0.142395 & 0.123545 & 0.11962 & 0.120094 & 0.12087 \\
$e_{+}$ & 0.02583 & 0.066779 & 0.091896 & 0.08167 & 0.071473 & 0.068601 & 0.068795 \\
\hline
\end{tabular}


Table 6. Variance Decomposition

\begin{tabular}{llllllll}
\hline & 1 & 4 & 8 & 12 & 16 & 20 & 24 \\
\hline$p_{t}^{d}$ & 88.25366 & 70.10771 & 63.60983 & 56.5907 & 51.85848 & 48.36843 & 45.60025 \\
$i_{t}$ & 11.30335 & 29.48657 & 33.78672 & 38.90545 & 42.6958 & 45.68607 & 48.09568 \\
$e_{t}$ & 0.442983 & 0.405717 & 2.603447 & 4.503844 & 5.445714 & 5.945504 & 6.304067 \\
S.E. & 0.191774 & 0.563565 & 0.735732 & 0.803615 & 0.851068 & 0.895785 & 0.939822 \\
& & & & & & & \\
\hline
\end{tabular}
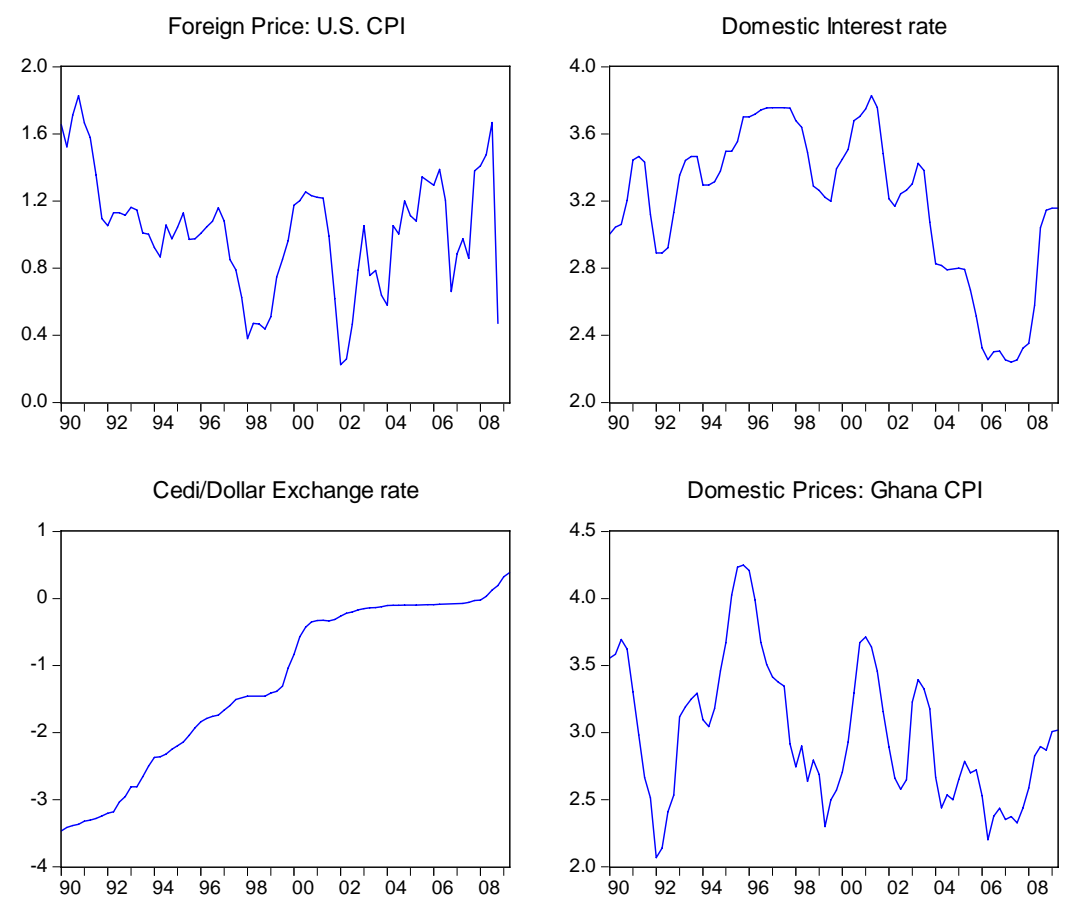

Figure 1. Logarithm of variables

\section{Response to Generalized One S.D. Innovations}

Response of Domestic prices to Exchange rate

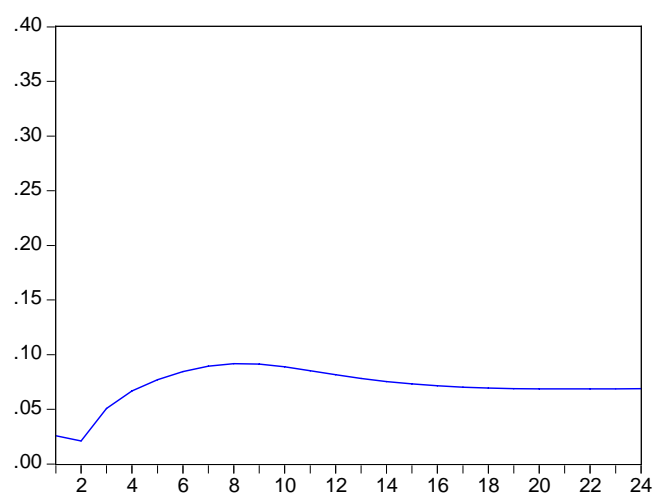

Figure 2. Impulse Response to $1 \%$ innovation in exchange rate 